\title{
Environmental and non-infectious factors in the aetiology of pharyngitis (sore throat)
}

\author{
Bertold Renner • Christian A. Mueller • \\ Adrian Shephard
}

Received: 20 January 2012/Revised: 22 July 2012 / Accepted: 25 July 2012 / Published online: 14 August 2012

(C) The Author(s) 2012. This article is published with open access at Springerlink.com

\begin{abstract}
Objectives The aim of this review is to examine the causes, pathophysiology and experimental models of noninfectious pharyngitis (sore throat).

Introduction The causes of sore throat can be infectious (viruses, bacteria, and fungi) or non-infectious, although the relative proportion of each is not well documented.

Methods A PubMed database search was performed for studies of non-infectious sore throat.

Results and conclusions Non-infectious causes of sore throat include: physico-chemical factors, such as smoking, snoring, shouting, tracheal intubation, medications, or concomitant illness; and environmental factors including indoor and outdoor air pollutants, temperature and humidity, and hazardous or occupational irritants. The pathophysiology underlying non-infectious sore throat is largely uncharacterised, although neurogenic inflammation looks to be a promising candidate. It is likely that there will be individual disposition factors or the coincidence of more than one irritant with possible - up to now unknown-interactions between them. Therefore, experimental models with defined conditions and objective endpoints are needed. A new model
\end{abstract}

Responsible Editor: Michael Parnham.

B. Renner $(\bowtie)$

Department of Experimental and Clinical Pharmacology, University of Erlangen-Nuremberg, Krankenhausstr. 9, 91054 Erlangen, Germany

e-mail: bertold.renner@pharmakologie.uni-erlangen.de

C. A. Mueller

Department of Otorhinolaryngology,

Medical University of Vienna, Vienna, Austria

A. Shephard

Reckitt Benckiser Group plc, Slough, UK using cold dry air to directly induce pharyngeal irritation in humans, with pharyngeal lavage to measure biomarkers, may provide a useful tool for the study of mechanisms and treatment of non-infectious sore throat.

Keywords Air pollution - Cold dry air .

Experimental model · Inflammation ·

Occupational exposure · Therapy · Pain

\section{Introduction}

Pharyngitis is inflammation of the oropharynx. It is commonly referred to as sore throat, although this term is often used imprecisely and is poorly defined. Hence, whilst sore throat may be the symptom described by the patient, examination might also reveal nasopharyngitis (that is, including the nasopharyngeal mucosa). The exact site of the irritation/inflammation is often not identified, with some studies relying on a patient-reported diagnosis (that is, 'sore throat'). These factors potentially complicate the study (and treatment) of sore throat. The following review will focus on sore throat as the primary symptom, which implies reported irritation and pain caused by inflammation and/or irritation of the oro (medium part) and hypopharynx (lower part of the pharynx). As mentioned, there exist also overlapping symptoms to nasopharyngitis (upper part of the pharynx) but rhinitis or rhinosinusitis are usually diagnosed in those patients and sore throat is not the primary symptom.

Sore throat may have an infectious or non-infectious aetiology, although these sometimes overlap. Most cases are infectious, with a large proportion (up to $40 \%$ ) caused by rhinovirus and adenovirus. Other viruses including coronavirus, influenza, parainfluenza, Epstein Barr, and 


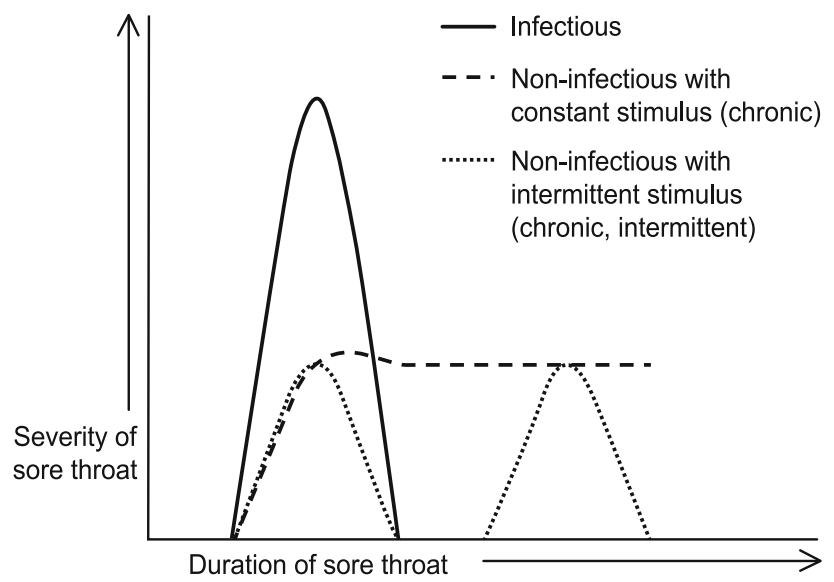

Fig. 1 Schematic representation of typical course of sore throat of infectious and non-infectious aetiology

herpes simplex have also been implicated [1]. Of the bacterial sore throats, group A $\beta$-haemolytic streptococcus is most frequently $(5-36 \%)$ isolated $[1,2]$. Other organisms to which sore throat has been attributed include Mycoplasma pneumonia and Arcanobacterium haemolyticus [1]. Rarely, candidal infections and other fungi and parasites have also been observed [1].

A proportion of sore throats have non-infectious aetiologies, although the relative prevalence versus infectious cases is not well documented. This is probably because it is a costly and difficult area to study. The non-infectious causes of sore throat are extremely varied, and include physico-chemical factors (for example smoking, snoring, shouting, drugs) and environmental factors (for example pollution, temperature, humidity/air conditioning). An approximation might be obtained by identifying people with sore throat in the absence of any other symptom (e.g. rhinosinusitis) or with persistent sore throat (Fig. 1); but this does not definitively exclude a viral, bacterial, or fungal cause. In fact, quantifying the prevalence of non-infectious sore throat would likely require the active identification and exclusion of all potential infectious causes.

Overall, sore throat is a very common complaint and a frequent reason for seeking medical care [3]. Of 15,788 respondents (aged 14 years or older) in a Scottish postal survey, $31 \%$ reported they had experienced severe sore throat or tonsillitis in the previous year [4]. In the USA, acute pharyngitis accounts for 1-2\% of all visits to outpatient departments, physician offices, and emergency departments [5]. Many people do not seek medical care when they have a sore throat [6], although geographical variation is considerable, dependent on social factors, access to and cost of healthcare, and attitudes to antibiotic prescribing.

When patients with sore throat do present to primary care, the optimal management is controversial. This is because, relatively rarely, sore throat can be serious [7].
Furthermore, whilst antibiotics may provide only modest absolute benefits [8], there are few other prescription options available for sore throat. Recurrent severe episodes of sore throat might indicate tonsillectomy, while concurrent severe symptoms such as difficulty breathing or swallowing usually require hospital admission [2]. The main cause for concern though is the risk of rheumatic fever and suppurative complications in patients with group A $\beta$-haemolytic streptococcus and for this reason many doctors, particularly in the USA, exercise caution [9]. Other potential complications include post-viral olfactory dysfunction [10] and anosmia (which might be prevented by vaccination in the future). A review of guidelines found that recommended management strategies vary widely [11]. In some countries sore throat is considered to be selflimiting and swabbing and antibiotics are not routine, whereas, others recommend microbiological investigation with subsequent antibiotics for confirmed streptococcal cases [11]. Non-steroidal anti-inflammatory drugs and paracetamol are recommended for symptomatic relief [2, 12], while the relative risks and benefits of corticosteroids require further study $[2,13]$. The management of sore throat is, therefore, far from standardised or evidence based.

It is clear then that the majority of people with sore throat have a benign self-limiting illness and many do not present for medical care [6]. Amongst these are a largely unquantified population with non-infectious aetiologies, about which little is understood and for whom the optimal treatment strategy is unclear. The objective of this review was to collate the information on non-infectious sore throat, particularly the proposed aetiologies and mechanisms involved.

\section{Causes of non-infectious sore throat}

\section{Physico-chemical factors}

A wide variety of physico-chemical factors have been implicated in causing sore throat, including cigarette smoke inhalation, snoring, tracheal intubation, shouting, and concomitant illness or drug effects.

Smoking is a risk factor for sore throat [14], in both smokers themselves and in those exposed to secondary smoke (passive smoking). Cigarette smoking was significantly associated with sore throat/cough in US college students [15], and frequency of cigarette smoking and sore throat were correlated in Japanese women [16]. Passive smoking was significantly associated with sore throat in 46 French non-smokers [17], 382 Australian non-smoking indoor workers [18], and non-smoking Australian nightclub and casino workers [19]. Furthermore, a questionnaire 
study reported a significant relationship between children's sore throats and maternal smoking [20].

Snoring is frequently associated with sore throat, and the two have risk factors such as smoking [21] in common, although the direction of causality is not always clear. A high frequency of sore throat is a risk factor for habitual snoring in children [22] and sore throat was reported by over half of those snoring children who were subsequently diagnosed with obstructive sleep apnoea [23]. Sore throat may also be associated with obstructive sleep apnoea in adults [24]. Sleep apnoea is a key factor for the manifestation of secondary hypertension.

Tracheal intubation and laryngeal mask airways are common causes of sore throat in people undergoing general anaesthesia [24-27]. The reported incidence of postoperative sore throat varies widely, but is generally higher for tracheal intubation than for laryngeal mask airway [28]. For patients undergoing tracheal intubation, an incidence of around 28-45.5\% [27, 29] — and as high as $70 \%$ [30]has been reported. For laryngeal mask airway, the incidence is lower-in the region of 3.5-21.4\% [27, 29, 31].

Shouting and voice loading may cause sore throat, as reported by people in professions that require use (and overuse) of their voice for their work. For example, aerobics instructors have reported an increased incidence of sore throat unrelated to illness since beginning instructing [32] and the frequency of aerobics classes has been shown to significantly correlate with sore throat symptoms in instructors [33]. Sore throat is also reported by school teachers [34]. Furthermore, sore throat can occur as a secondary consequence of functional dysphonia [35] as well as vice versa.

Drug-induced sore throat is a notable adverse effect of some medications, including angiotensin-converting enzyme (ACE) inhibitors [36] and chemotherapy agents. Sore throat is also a common problem in asthmatics taking inhaled corticosteroids [37-39], although these data may be in part confounded by a potential steroid-induced increased susceptibility to infection, including mycoses. In fact, people taking a wide variety of other drugs frequently report sore throat as an adverse effect, but in many cases the symptom will be coincidental (that is, probably infectious sore throat and at a similar rate to placebo).

Concomitant illness can directly result in sore throat. For example, Kawasaki disease (a mucocutaneous vasculitis) typically causes pharyngitis in both adults and children [40]. Furthermore, chronic pharyngitis is a common manifestation of gastroesophageal reflux disorder [41], with this presentation now termed laryngopharyngeal reflux disorder [42]. While in these cases the sore throat can be considered to be a direct manifestation of the underlying condition, other illnesses may be associated with sore throat due to a consequent increased predisposition to infection. This may be the case for the often cited link with thyroid disease, where $41 \%$ of patients with newly diagnosed thyroiditis report sore throat as a first symptom [43].

\section{Environmental factors}

A wide variety of environmental factors have been cited as causes of sore throat, including general air pollution, specific pollution related to occupation, hazard, or industry, and pollution encountered in indoor environments. However, because the data are often epidemiological and individual pollutants are rarely emitted in isolation, it is not always possible to identify the precise cause of symptoms. Patients with allergic rhinitis [44] as well as those with postnasal drip [7], non-allergic rhinitis, and persistent cough may also experience sore throat as a secondary symptom.

Ambient air pollution is a common cause of sore throat. The factors implicated include ozone, nitrogen oxides, and fine dust.

Urban living and traffic fumes are frequently associated with sore throat. In children in Hong Kong, sore throat decreased when fuel sulphur levels were reduced [45], whilst exposure to vehicle emissions was linked with throat pain and chronic pharyngitis in Shanghai bus drivers/conductors/taxi drivers [46] and lack of air conditioning with frequent sore throat in Hong Kong bus and tram drivers [47]. Nitrogen dioxide has also been implicated [48, 49], as well as photochemical oxidants such as ozone $\left(\mathrm{O}_{3}\right)[50,51]$.

Occupational or hazard-associated irritants that have been reported to cause sore throat include particulates, fumes, chemicals, and odours. Laryngitis has also been reported [52].

Particulates and fumes from a wide variety of industries have been implicated in sore throat, including pulp mills [53], woodworking [54], cement works [55], brick kilns [56], and factory exhaust emissions [57]. The burning of gas creates multiple pollutants, including nitrogen oxides, particulates, and volatile organic compounds, and gasrelated pollution has been linked with sore throat in several studies [58, 59]. Cooking and fires are important sources of pollutants worldwide [60], and in US non-smoking women, each hour of fireplace use was associated with (little but measurable) increased episodes of sore throat (relative risk 1.04; $95 \%$ CI 1.00-1.08) [61].

A variety of chemicals have been reported to cause sore throat including organic screen-printing solvents [62], boron oxide, boron acid, and borax dust [63, 64], fluorinated hydrocarbons [65], machining coolants in the metal working industry [66], nitrogen trichloride from indoor swimming pools [67], chemical odours [68], and crude oil spills [69-71]. In the newspaper printing industry-which 
uses multiple chemicals including organic solvents, filler materials, and inks-a higher than expected incidence of chronic pharyngitis has been reported [72]. Sore throat is also a frequently-reported (72\%) symptom [73] in people with multiple chemical sensitivity syndrome.

The US World Trade Center disaster (9/11) resulted in uncharacterised hazardous exposures that are thought to be the cause of the upper airway inflammation seen in many of those exposed [74]. In 10,378 fire fighters, sore throat was rare before the disaster $(3.2 \%$ reported frequent sore throat), but was the most common respiratory symptom in the year afterwards $(62.4 \%)$, declining and plateauing thereafter (36\% in 2 years, and $37 \%$ in 4 years) [75]. Along with cough, sore throat was considered to be the most sensitive initial indicator of respiratory insult [75].

Volcano eruptions emit sulphur dioxide and other gasses that may react with atmospheric components, and have been reported to cause sore throat. For example, sore/dry throat was significantly associated with volcanogenic sulphur dioxide and fine sulphate particles in Hawaii [76-78], and the hourly incidence of sore throat showed clear exposure-response relationships with post-eruptive $\mathrm{SO}_{2}$ concentrations [79].

Complaints of sore throat are frequent in communities with confined animal facilities, wastewater treatment plants, and biosolids recycling operations [80]. Sore throat was also significantly more prevalent in Greek solid waste collectors versus other workers [81]. Pig farming may be a particular cause of sore throat in nearby residents [82], with a $10 \mathrm{EU} /$ $\mathrm{mg}$ increase in endotoxin being associated with increased $\log$ odds $(0.10 \pm 0.05)$ of sore throat [83]. Farmers are additionally exposed to pesticides, and this was attributed as the cause of pharyngitis in a study of farmers versus other workers in the United Arab Emirates [84].

These studies reveal that occupational and hazardassociated irritants, including particulates, chemicals, fumes and gasses, and endotoxin are well-documented causes of sore throat.

Indoor air pollution causes sick building syndrome, including sore throat. In the building assessment survey and evaluation (BASE) study, $7.1 \%$ of workers in 41 large office buildings reported sore or dry throat [85]. The underlying source of pollutants is thought to be poorly maintained moisture-related heating, ventilating, and air-conditioning components such as cooling coils and humidification systems [86]. Thus, symptom prevalence is higher in buildings ventilated mechanically or with air-conditioning compared with naturally ventilated buildings $[87,88]$. The specific pollutants responsible are not well characterised. Ozone brought into the building through the ventilation system [89], and its interaction with ventilation filters [90], has been implicated, as have particulates [91]. Damp and mouldy buildings also cause sore throats $[92,93]$.
Temperature and humidity affect mucus membranes, and have been linked with sore throat symptoms. Heated air causes nasal pain [94] and working regularly in a cold environment causes rhinitis and sore throat as well as changes in lung function [95]. Humidity is also important, with the overall intensity of sick building syndrome symptoms increasing when indoor air is not humidified [96]. Experimentally, cold dry air induces nasal inflammation [97, 98], and causes more nasal pain than humidified dry air [94]. However, a population-based study showed that both cold temperature and low humidity appear to independently increase the risk of sore throat [99].

\section{Management of non-infectious sore throat}

There has been little systematic assessment of treatments for sore throat of non-infectious aetiology, and the field is hampered by a lack of objective outcomes, with most studies relying on subjective (self-reported) endpoints. By definition, studies of antibiotic treatment for sore throat are in infectious populations. Studies of non-antibiotic treatment are generally similarly confounded by the inclusion criteria 'acute pharyngitis' or 'chronic pharyngitis' which will likely be of mixed aetiology. A population with sore throat secondary to functional dysphonia might better reflect the non-infectious aetiologies, but such studies are few. Defined non-infectious study populations are, therefore, required. Many of the current data are unreliable for determining the efficacy of treatments for non-infectious sore throat, although some parallels can be drawn.

It is likely that the efficacy of non-antibiotic treatments that has been reported in acute (mostly infectious) sore throat might also be seen in non-infectious sore throat. This extrapolation is based on the assumption that simple analgesia and anti-inflammatory effects are likely to be effective whatever the aetiology, especially if neurogenic inflammation is involved (see below). A systematic review in acute sore throat found that treatments effective on early outcomes $(<24 \mathrm{~h})$ included steroids, non-steroidal antiinflammatory drugs (NSAIDs), caffeine, and paracetamol, while paracetamol and NSAIDs also had a benefit on later ( $>24 \mathrm{~h}$ ) outcomes [12]. These treatments might also work for non-infectious sore throat.

There have been some studies in chronic pharyngitis, but these are mostly small. Flurbiprofen has been shown to be effective [100], as have Chinese herbs used in combination with acupuncture [101]; Chinese herbs have been the subject of a systematic review [102]. Inhaled natural ether oils have also been used [103], although the composition is mostly unknown. A Russian study of 22 patients with aggravated chronic subatrophic pharyngitis against a 
background of acute respiratory viral infection showed that amylmetacresol/dichlorobenzyl alcohol lozenges (Strepsils ${ }^{\circledR}$, Reckitt Benckiser Healthcare Ltd) resulted in a marked and durable reduction in pain symptoms, which was reported immediately after the first dose, and resulted in average pain scores three times lower than the control group by day 8 [104]. Although the aetiology of sore throat in these patients is not always well defined, several treatments show promise for the management of persistent sore throat.

Studies in defined non-infectious sore throat populations are few. Nimesulide and flurbiprofen were both found to be effective in a randomised study of 60 patients with noninfectious acute inflammation of the upper respiratory tract [105]. Experimentally, paracetamol in combination with caffeine reduces the nasal tonic pain elicited by dry air provocation, and caffeine enhances and prolongs the analgesia compared with control [106], supporting a role for analgesics in non-infectious sore throat. Patients with sore throat secondary to functional dysphonia may respond to treatment of the underlying cause with vocal hygiene, voice training, avoidance of irritants and allergens, and co-medications (e.g. proton pump inhibitors, anti-allergic drugs).

The most frequently studied non-infectious population is that of postoperative sore throat and owing to its high incidence, a great many studies have been conducted in this area. For example, postoperative sore throat can be prevented with inhaled fluticasone propionate [107], intravenous dexamethasone [108], and lidocaine [30]. Other remedies include ketamine gargle [109], topical NSAIDs including benzydamine [110], perioperative amylmetacresol/dichlorobenzyl alcohol lozenges (Strepsils ${ }^{\circledR}$ ) [111], liquorice [112], and an azulene derivate from chamomile [113].

These studies in defined populations with non-infectious sore throat add to the data obtained in studies of less welldefined acute and chronic sore throat. Although there is currently a lack of rigorous trials of treatments for noninfectious sore throat, there are enough data to suggest there may be several effective strategies. The lack of a suitable preclinical model hampers efforts to identify effective new treatments.

\section{The mechanism of non-infectious sore throat}

The treatment of non-infectious sore throat could be improved if the mechanisms were fully understood. However, the underlying pathophysiology, and components such as individual disposition and potential receptors and their interaction with irritants, are not yet well characterised. To complicate matters, the underlying mechanism may vary with aetiology. Inflammation is a logical consequence of infection of the upper respiratory tract. Inflammation has also been implicated in non-infectious aetiologies, with inflammatory cells and mediators isolated from the upper respiratory tract (for example [114, 115]).

Mechanical trauma and injury is almost certainly the precipitating factor in postoperative sore throat [25], as supported by the preventive efficacy of some lubricants [116]. The inflammatory response has been replicated in a swine model, with elevated interleukin (IL) 6 and polymorphonuclear leukocytes found in tracheal lavage fluid [117]. However, the precise aetiology and location of postoperative sore throat remains unknown [25]. Factors such as tracheal-tube size [118] and cuff design [119] have been implicated during intubation [26], and sore throat following the use of a laryngeal mask airway appears to be related to the technique of insertion [31] and intracuff pressure [26]. The problem is more common in older age groups, and is related to grade of difficulty of intubation, duration of surgery, and patient's position during surgery [29], with all factors probably reflecting an increased risk of trauma.

The mechanism underlying sore throat in people with gastroesophageal reflux disorder is likely to be chemical, that is, due to refluxed gastric content, although indirect effects through vagal (sensory) mechanisms have also been implicated [42].

In rhinitis, pharyngeal irritation has been attributed to the lymphoid hypertrophy and prominence of adenoidal and tonsillar tissue, which results from chronic allergic inflammation of the upper airway [120], and kinins generated in nasal secretions have been implicated [121]. The mediators released after nasal challenge with allergens or cold dry air are remarkably similar, including histamine, leukotrienes, prostaglandin D2, and TAME-esterase [122]. The mechanism of cold air-induced rhinitis is well-characterised, being associated with nasal mast cell activation and sensory nerve stimulation (irritation) that generates a cholinergic reflex leading to rhinorrhoea [98]. It seems likely that the same mechanism may be responsible for cold-induced sore throat-a useful experimental model (see below).

Snoring is problematic in terms of identifying the mechanism because although sore throat may cause snoring, snoring may also cause sore throat [22]. The mechanism is likely to be mechanical and similar to that seen with dry air; sore throat is also associated with mouth breathing [7, 22], obviously due to drying out of the pharyngeal mucosa caused by unfiltered, unwarmed, nonhumidified air passage. Snoring-induced vibrations have also been implicated in sore throat [22]. Similarly, it may be physical stress on the pharynx that causes sore throat following shouting and voice loading. Along with such 
mechanical mechanisms, emotional stress and stressinduced subjective factors may also play a role, perhaps in combination with muscle spasm. Excessive tension of the (para) laryngeal musculature (due to psychological and emotional factors, vocal misuse, or compensation for underlying problems such as infection) [123] may result in pain that could promote the persistence of lesions in the laryngeal and pharyngeal mucosa.

The drugs that frequently (2-40\%) cause sore throat or dry cough as a recognised adverse effect include ACE inhibitors, which increase pro-inflammatory mediators such as kinins, substance $P$, and prostaglandins [124]. For this unwanted drug effect genetic predisposition factors were found on corresponding receptors [124]. Switching from ACE inhibitors to angiotensine receptor blockers is the most accepted alternative to prevent elevated cytokines. The mechanism by which inhaled corticosteroids cause sore throat is less certain [37, 39]. Histologically, an inflammatory infiltrate has been reported in some patients [37] and locally-deposited steroid is likely to be a factor [125]. In contrast, oral steroids alleviate the pain of acute sore throat [13], probably due to their anti-inflammatory action (because of the risk of side effects they are not a routine therapeutic option in the long term). Chemotherapy and radiotherapy cause sore throat as a consequence of oropharyngeal mucositis [126].

These physico-chemical causes of sore throat, while not fully elucidated, at least have plausible putative mechanisms. The situation for many environmental insults is more complex. Throughout the literature, the term 'irritants' is used, but documented evidence of their identities or the mechanism by which they might irritate and inflame mucous membranes is scarce. For example, is it a physical interaction or do the irritants bind to receptors that trigger a deleterious response that manifests symptomatically as sore throat? Identification of such receptors would certainly go a long way to establishing the mechanism and providing a therapeutic target.

Tobacco smoke is an often cited irritant [14]. It irritates the stratified squamous epithelium of the oropharyngeal mucosa [127] causing damage and reduced mucociliary clearance, and impairs the immune response [128]. Nicotine binds to the nicotinic acetylcholine receptor on sensory neurons [129, 130], and this is one of the proposed mechanisms for irritation and pain caused by cigarette smoke. However, chronic pain and an acute analgesic effect of nicotine attenuated by desensitisation and/or upregulation of the receptor on chronic exposure have also been suggested [131]. Smoking also alters the resident flora [132] predisposing to infection. Conversely, abstaining from smoking for even one week causes a significant increase in reports of sore throat $(P=0.049)$ and other cold symptoms [133]. This is perhaps due to reduced salivary immunoglobulin A [134]. Furthermore, the reason for this unexpected observation might be rebound sensitisation of (nicotinic acetylcholine) receptors.

Ozone has an inflammatory effect on both the upper and lower respiratory tract, characterised by polymorph infiltration and release of pro-inflammatory cytokines [135137], although the specifics relating to sore throat are less certain. The underlying mechanism is proposed to include a direct effect of ozone on respiratory tract cell membranes and fluid, with lipid ozonation products activating specific lipases, triggering the release of endogenous mediators of inflammation [138, 139] such as prostaglandin E, IL8, thromboxane B2 and calcitonin gene-related peptide.

A straightforward chemical mechanism may underlie the irritant effect of some environmental pollutants. For example, in the presence of metal catalysts and moist air, $\mathrm{SO}_{2}$ forms sulphuric acid and ammonium sulphate [45]. Other pollutants probably include $\mathrm{NO}_{2}$, and boron oxide and boron acid. Sore throat in response to chemical odours [68] could be due to irritation by the odorants themselves or co-pollutants, or a learned aversion [140] which is wellestablished for odorants.

Particulate matter, which contains both organic and inorganic constituents, is associated with airway inflammation, apoptosis, genotoxicity, and oxidative stress [141-143]. Cement dust induces atrophic and hypertrophic changes in nasal and pharyngeal mucosa and chronic exfoliative bronchitis in animal models [144]. Much of the extensive research in the particulates field has been conducted in vitro, but humans exposed to fuel oil ash have evidence of inflammation, with increased IL8 and polymorphs in nasal lavage fluid [114]. Induced sputum studies of fire fighters 10 months after the World trade centre disaster found levels of neutrophils and eosinophils increased in relation to the intensity of dust exposure [115].

Neurogenic inflammation may be responsible for the airway response to particulate matter and other environmental irritants such as ozone or sulphur dioxide [145, 146]. The irritants are proposed to interact with transient receptor potential (TRP) channels. These ion channels are found on sensory nerve fibres as well as immune and nonimmune cells in the respiratory tract, and their activation results in the release of neuropeptides, such as calcitonin gene-related peptide and substance $\mathrm{P}$, that trigger inflammation [147]. TRP channels are normally involved in detection of the thermal, mechanical, and chemical stimuli that are essential for survival [148].

Activated and sensitised TRP channels, particularly TRPV1 and TRPA1, have been implicated in chronic airways diseases (chronic obstructive pulmonary disease and asthma) and the respiratory response to environmental irritants [148, 149]. TRPV1 is activated by the potent respiratory irritant capsaicin, but also by extracellular 
protons (generated during tissue acidosis and ischaemia) and heat [149], and is also directly sensitised by nicotine [148]. TRPA1 is activated by chlorine, reactive oxygen species, and noxious constituents of smoke and smog [149], as well as ginger and bradykinin [150]. It appears that reactive respiratory irritants may activate TRPA1 by covalent modification, with glutathione depletion perhaps prolonging the effect [149]. The cumulative effect may result in a reduced threshold for TRPA1 activation, such that even low levels of smog or indoor pollutants elicit a response [149].

Along with this direct activation of TRP channels by irritants, the pain associated with inflammation may also be mediated by TRP channels. TRPV1 and TRPA1 are both activated and sensitised through inflammatory receptor pathways [149]. Hence, when pro-inflammatory mediators (such as histamine, prostaglandins, cysteinyl leucotrienes, proteases, nerve growth factor, and bradykinin) bind to their respective receptors on sensory neurons, this indirectly results in TRP activation [149] via the endogenous activating lipids produced by the phospholipase $\mathrm{C}$ and phospholipase A2 pathways [148].

The field of TRP channel research is rapidly expanding, as it becomes clear that these ion channels may be involved in a vast range of diseases and chronic pain situations. Because pain can be the result of overly sensitised TRP channels, it follows that TRP desensitisation using agonists might provide relief [151]. This is supported by animal models, where capsaicin desensitises the acute and inflammatory airway response to a variety of noxious stimuli [149].

With the sensory role of TRPs in detecting a wide range of thermal, mechanical, and chemical stimuli, TRP channel activation and sensitisation-and the consequent triggering of inflammation-potentially accounts for many of the aetiologies of non-infectious sore throat, providing the possibility of interactions of TRP channels and targets for intervention. Along with TRPV1 and TRPA1, other possible mechanisms and targets for intervention include: the somatosensory TRP channels, TRPM8, TRPV2 and TRPV4 [152]; acid-sensing ion channel in the airway, which detects acidity and toxic gasses [146]; and the neuronal nicotinic acetylcholine-receptor $[129,130]$.

\section{Experimental models of non-infectious sore throat}

In order to fully elucidate the pathophysiology of noninfectious sore throat, as well as assess the efficacy of any potential treatments, models with defined conditions and objective endpoints are required.

Many of the currently available models are not specific for sore throat, and use subjective endpoints. Since the sensation of pain is so subjective, asking patients to rate its severity can often be the most appropriate endpoint. Models for the study of non-allergic rhinitis and cough, but not specifically sore throat, include challenge with methacholine, histamine, capsaicin [153], mechanical pressure [154], and citric acid [155, 156]. In contrast, nasal provocation with bradykinin induces sore throat as well as rhinitis [121]. The sore throat pain model [157, 158], by definition, provides specificity. However, it requires patients to rate their throat pain on a visual analogue rating scale and, as such, the endpoint is subjective.

There are some more specific animal models with objective endpoints. Pharyngeal inflammation was induced in a rat model by applying capsaicin directly to the pharyngeal mucosa [159]. Intubation has been used to induce pharyngeal inflammation in a swine model [117] and laryngeal inflammation in a rat model [160], with analysis of biomarkers. Well-defined human models of pharyngeal irritation with objective endpoints are generally lacking. One that is in research use is the Tonsilliopharyngeal assessment (TPA) scale which is based on a clinical examination of the throat [158], although this still depends on the clinician's judgement. Currently, any correlation between subjective and objective endpoints is therefore untested.

In humans, biomarkers, such as immune cells and inflammatory mediators, are often experimentally measured in epidemiological studies, providing an objective marker of airway inflammation. However, unless obtained from a biopsy (which is too invasive for routine use), these are not necessarily specific to the pharyngeal mucosa. For example, analysis of bronchiolar lavage fluid reflects inflammation occurring in the lungs but is relatively invasive to perform, so not in common use. Tracheal lavage and induced sputum techniques also sample mostly the lower respiratory tract. Nasal lavage, which samples the upper respiratory tract, gets closer to the pharyngeal mucosa, but is still relatively specific to the nasal epithelium. In contrast, pharyngeal lavage [161] is site specific.

In humans, nasal challenge with cold dry air has been used to experimentally replicate cold air-induced rhinitis [97, 98, 153] and can be combined with the objective analysis of biomarkers of nasal inflammation.

\section{A new model of pharyngeal inflammation in humans}

The lack of suitable models for the study of non-infectious sore throat has hampered progress in elucidating mechanisms and identifying treatments. A new model has been developed using cold dry air (CDA) to experimentally induce controlled inflammation in the pharynx of healthy volunteers. The inflammation is then quantified by measuring inflammatory mediators in pharyngeal lavage fluid [unpublished]. 
The model is a promising tool for future research because it induces reversible pharyngeal irritation, in controlled conditions, and is amenable to a crossover study design. It may provide a valuable research tool and an objective way of measuring the therapeutic potential of treatments. Furthermore, this procedure may also allow for research in occupational and environmental medicine where exposure limits for single potential irritants exist but interactions are not yet well established. In this way, a CDA stimulus may be combined with one or two potential irritants in order to generate comparable results in crossover study designs.

\section{Conclusions}

Despite how common non-infectious sore throat is, little is understood about how it is caused by such a wide variety of physico-chemical and environmental factors. It is possible that in many cases the cause of persistent non-infectious sore throat involves a combination of physico-chemical and environmental factors. Inflammatory processes (of various mechanisms, including neurogenic inflammation) appear to underlie sore throat of non-infectious aetiologies, and in many cases this may be the source of the pain. Cytokine receptors and TRP channels seem to be involved in the transduction pathways. Inflammation also underlies infectious sore throat, so many of the therapeutic options may be also appropriate for non-infectious sore throat. Indeed, although limited, the literature suggests that appropriate treatment options for non-infectious sore throat may include drug therapy. However, the lack of suitable human experimental models hampers the identification of drug therapy (for example topical TRP antagonists). A new model using cold dry air and pharyngeal lavage may provide a useful tool for the study of mechanisms-including receptor interactions - and treatment of non-infectious sore throat.

Acknowledgments Editorial assistance for the development of this article was provided by Elements Communications Ltd, UK, supported by Reckitt Benckiser Healthcare Ltd.

Open Access This article is distributed under the terms of the Creative Commons Attribution License which permits any use, distribution, and reproduction in any medium, provided the original author(s) and the source are credited.

\section{References}

1. Middleton DB. Pharyngitis. Prim Care. 1996;23(4):719-39.

2. SIGN. Management of sore throat and indications for tonsillectomy. A National clinical guideline, 117. Scottish Intercollegiate guidelines network, April 2010. Available at: http://www.sign.ac. uk/pdf/sign117.pdf. Accessed 27 October 2011.
3. Vincent MT, Celestin N, Hussain AN. Pharyngitis. Am Fam Physician. 2004;69(6):1465-70.

4. Hannaford PC, Simpson JA, Bisset AF, Davis A, McKerrow W, Mills R. The prevalence of ear, nose and throat problems in the community: results from a national cross-sectional postal survey in Scotland. Fam Pract. 2005;22(3):227-33.

5. Tan TQ. The appropriate management of pharyngitis in children and adults. Expert Rev Anti Infect Ther. 2005;3(5):751-6.

6. Little PS, Williamson I. Are antibiotics appropriate for sore throats? Costs outweigh the benefits. BMJ. 1994;309(6960):1010-1.

7. Stephenson KN. Acute and chronic pharyngitis across the lifespan. Lippincotts Prim Care Pract. 2000;4(5):471-89.

8. Del Mar CB, Glasziou PP, Spinks AB. Antibiotics for sore throat. Cochrane Database Syst Rev. 2006;(4):CD000023.

9. Matthys J, De Meyere M, van Driel ML, De Sutter A. Differences among international pharyngitis guidelines: not just academic. Ann Fam Med. 2007;5(5):436-43.

10. Doty RL. The olfactory system and its disorders. Semin Neurol. 2009;29(1):74-81.

11. Chiappini E, Regoli M, Bonsignori F, Sollai S, Parretti A, Galli L, de Martino M. Analysis of different recommendations from international guidelines for the management of acute pharyngitis in adults and children. Clin Ther. 2011;33(1):48-58.

12. Thomas M, Del Mar C, Glasziou P. How effective are treatments other than antibiotics for acute sore throat? Br J Gen Pract. 2000;50(459):817-20.

13. Korb K, Scherer M, Chenot JF. Steroids as adjuvant therapy for acute pharyngitis in ambulatory patients: a systematic review. Ann Fam Med. 2010;8(1):58-63.

14. Centers for Disease Control (CDC). Discomfort from environmental tobacco smoke among employees at worksites with minimal smoking restrictions-United States, 1988. MMWR Morb Mortal Wkly Rep. 1992;41(20):351-4.

15. An LC, Berg CJ, Klatt CM, Perry CL, Thomas JL, Luo X, Ehlinger E, Ahluwalia JS. Symptoms of cough and shortness of breath among occasional young adult smokers. Nicotine Tob Res. 2009;11(2):126-33.

16. Asahi S, Uehara R, Watanabe M, Tajimi M, Oki I, Ojima T, Nakamura Y, Oguri S, Okayama A, Matsumura Y, Yanagawa H. Respiratory symptoms correlating to smoking prevalence: the national nutrition survey and the national life-style survey in Japan. J Epidemiol. 2003;13(4):226-31.

17. Ségala C, Poizeau D, Neukirch F, Aubier M, Samson J, Gehanno P. Air pollution, passive smoking, and respiratory symptoms in adults. Arch Environ Health. 2004;59(12):669-76.

18. Wakefield M, Trotter L, Cameron M, Woodward A, Inglis G, Hill D. Association between exposure to workplace second hand smoke and reported respiratory and sensory symptoms: crosssectional study. J Occup Environ Med. 2003;45(6):622-7.

19. Wakefield M, Cameron M, Inglis G, Letcher T, Durkin S. Second hand smoke exposure and respiratory symptoms among casino, club, and office workers in Victoria, Australia. J Occup Environ Med. 2005;47(7):698-703.

20. Willatt DJ. Children's sore throats related to parental smoking. Clin Otolaryngol Allied Sci. 1986;11(5):317-21.

21. Ekici M, Ekici A, Keles H, Akin A, Karlidag A, Tunckol M, Kocyigit P. Risk factors and correlates of snoring and observed apnea. Sleep Med. 2008;9(3):290-6.

22. Urschitz MS, Guenther A, Eitner S, Urschitz-Duprat PM, Schlaud M, Ipsiroglu OS, Poets CF. Risk factors and natural history of habitual snoring. Chest. 2004;126(3):790-800.

23. Richards W, Ferdman RM. Prolonged morbidity due to delays in the diagnosis and treatment of obstructive sleep apnea in children. Clin Pediatr (Phila). 2000;39(2):103-8.

24. Casale M, Rinaldi V, Bressi F, Di Peco V, Baptista P, Sadun B, Urrestarazu E, Trivelli M, Salvinelli F. A suitable test for 
identifying high risk adult patients of moderate-severe obstructive sleep apnea syndrome. Eur Rev Med Pharmacol Sci. 2008;12(4):275-80.

25. Scuderi PE. Postoperative sore throat: more answers than questions. Anesth Analg. 2010;111(4):831-2.

26. McHardy FE, Chung F. Postoperative sore throat: cause, prevention and treatment. Anaesthesia. 1999;54(5):444-53.

27. Higgins PP, Chung F, Mezei G. Postoperative sore throat after ambulatory surgery. Br J Anaesth. 2002;88(4):582-4.

28. Joshi GP, Inagaki Y, White PF, Taylor-Kennedy L, Wat LI, Gevirtz C, McCraney JM, McCulloch DA. Use of the laryngeal mask airway as an alternative to the tracheal tube during ambulatory anesthesia. Anesth Analg. 1997;85(3):573-7.

29. Ahmed A, Abbasi S, Ghafoor HB, Ishaq M. Postoperative sore throat after elective surgical procedures. J Ayub Med Coll Abbottabad. 2007;19(2):12-4.

30. Tanaka Y, Nakayama T, Nishimori M, Sato Y, Furuya H. Lidocaine for preventing postoperative sore throat. Cochrane Database Syst Rev. 2009;(3):CD004081.

31. Wakeling HG, Butler PJ, Baxter PJ. The laryngeal mask airway: a comparison between two insertion techniques. Anesth Analg. 1997;85(3):687-90.

32. Long J, Williford HN, Olson MS, Wolfe V. Voice problems and risk factors among aerobics instructors. J Voice. 1998;12(2): 197-207.

33. Komura Y, Inaba R, Fujita S, Mirbod SM, Yoshida H, Nagata C, Iwata $\mathrm{H}$. Health condition of female aerobic dance instructors. Subjective symptoms and related factors. Sangyo Igaku. 1992;34(4):326-34

34. Van Lierde KM, Claeys S, Dhaeseleer E, Deley S, Derde K, Herregods I, Strybol I, Wuyts F. The vocal quality in female student teachers during the 3 years of study. J Voice. 2010; 24(5):599-605.

35. Van Lierde KM, D'haeseleer E, Wuyts FL, De Ley S, Geldof R, De Vuyst J, Sofie C. The objective vocal quality, vocal risk factors, vocal complaints, and corporal pain in Dutch female students training to be speech-language pathologists during the 4 years of study. J Voice. 2010;24(5):592-8.

36. Fletcher AE, Palmer AJ, Bulpitt CJ. Cough with angiotensin converting enzyme inhibitors: how much of a problem? J Hypertens Suppl. 1994;12(2):S43-7.

37. Bhalla RK, Taylor W, Jones AS, Roland NJ. The inflammation produced by corticosteroid inhalers in the pharynx in asthmatics. Clin Otolaryngol. 2008;33(6):581-6.

38. Rachelefsky GS, Liao Y, Faruqi R. Impact of inhaled corticosteroid-induced oropharyngeal adverse events: results from a metaanalysis. Ann Allergy Asthma Immunol. 2007;98(3):225-38.

39. Roland NJ, Bhalla RK, Earis J. The local side effects of inhaled corticosteroids: current understanding and review of the literature. Chest. 2004;126(1):213-9.

40. Wolff AE, Hansen KE, Zakowski L. Acute Kawasaki disease: not just for kids. J Gen Intern Med. 2007;22(5):681-4.

41. Poelmans J, Tack J. Extraoesophageal manifestations of gastrooesophageal reflux. Gut. 2005;54(10):1492-9.

42. Barry DW, Vaezi MF. Laryngopharyngeal reflux: more questions than answers. Cleve Clin J Med. 2010;77(5):327-34.

43. Rotman-Pikielny P, Borodin O, Zissin R, Ness-Abramof R, Levy Y. Newly diagnosed thyrotoxicosis in hospitalized patients: clinical characteristics. QJM. 2008;101(11):871-4.

44. Coste A. ENT diseases associated with allergic rhinitis: a review of the literature. Ann Otolaryngol Chir Cervicofac. 2000;117(3): 168-73. French er.

45. Peters J, Hedley AJ, Wong CM, Lam TH, Ong SG, Liu J, Spiegelhalter DJ. Effects of an ambient air pollution intervention and environmental tobacco smoke on children's respiratory health in Hong Kong. Int J Epidemiol. 1996;25(4):821-8.
46. Zhou W, Yuan D, Ye S, Qi P, Fu C, Christiani DC. Health effects of occupational exposures to vehicle emissions in Shanghai. Int J Occup Environ Health. 2001;7(1):23-30.

47. Jones AY, Lam PK, Dean E. Respiratory health of bus drivers in Hong Kong. Int Arch Occup Environ Health. 2006;79(5):414-8.

48. Schwartz J, Zeger S. Passive smoking, air pollution, and acute respiratory symptoms in a diary study of student nurses. Am Rev Respir Dis. 1990;141(1):62-7.

49. Bauer U, Berg D, Kohn MA, Meriwether RA, Nickle RA. Acute effects of nitrogen dioxide after accidental release. Public Health Rep. 1998;113(1):62-70.

50. Schwartz J. Air pollution and the duration of acute respiratory symptoms. Arch Environ Health. 1992;47(2):116-22.

51. Kinney PL, Lippmann M. Respiratory effects of seasonal exposures to ozone and particles. Arch Environ Health. 2000;55(3): 210-6.

52. Williams NR. Occupational voice disorders due to workplace exposure to irritants-a review of the literature. Occup Med (Lond). 2002;52(2):99-101.

53. Vedal S, Petkau J, White R, Blair J. Acute effects of ambient inhalable particles in asthmatic and nonasthmatic children. Am J Respir Crit Care Med. 1998;157(4 Pt 1):1034-43.

54. Veneri L, Caso MA, Ravaioli M, Albonetti A, Ghini P, Mazzavillani M, Valentini MG. Study on prevalence of upper and lower airways disorders in woodworkers, using data from medical surveillance reports and exposure registers. G Ital Med Lav Ergon. 2007;29(3):833-5. Italian.

55. Ginns SE, Gatrell AC. Respiratory health effects of industrial air pollution: a study in east Lancashire, UK. J Epidemiol Community Health. 1996;50(6):631-5.

56. Joshi SK, Dudani I. Environmental health effects of brick kilns in Kathmandu valley. Kathmandu Univ Med J (KUMJ). 2008;6(1):3-11.

57. Ong SG, Liu J, Wong CM, Lam TH, Tam AY, Daniel L, Hedley AJ. Studies on the respiratory health of primary school children in urban communities of Hong Kong. Sci Total Environ. 1991;106(1-2):121-35.

58. Wong TW, Wong AH, Lee FS, Qiu H. Respiratory health and lung function in Chinese restaurant kitchen workers. Occup Environ Med. 2011;68(10):746-52.

59. Pilotto LS, Douglas RM, Attewell RG, Wilson SR. Respiratory effects associated with indoor nitrogen dioxide exposure in children. Int J Epidemiol. 1997;26(4):788-96.

60. Perez-Padilla R, Schilmann A, Riojas-Rodriguez H. Respiratory health effects of indoor air pollution. Int $\mathrm{J}$ Tuberc Lung Dis. 2010;14(9):1079-86.

61. Triche EW, Belanger K, Bracken MB, Beckett WS, Holford TR, Gent JF, McSharry JE, Leaderer BP. Indoor heating sources and respiratory symptoms in nonsmoking women. Epidemiology. 2005; 16(3):377-84.

62. Horstman SW, Browning SR, Szeluga R, Burzycki J, Stebbins A. Solvent exposures in screen printing shops. J Environ Sci Health A Tox Hazard Subst Environ Eng. 2001;36(10):1957-73.

63. Garabrant DH, Bernstein L, Peters JM, Smith TJ. Respiratory and eye irritation from boron oxide and boric acid dusts. J Occup Med. 1984;26(8):584-6.

64. Garabrant DH, Bernstein L, Peters JM, Smith TJ, Wright WE. Respiratory effects of borax dust. Br J Ind Med. 1985;42(12): 831-7.

65. Lyons RA, Wright D, Fielder HM, McCabe M, Gunneberg A, Nash P, Routledge P, Rees H. Investigation of an acute chemical incident: exposure to fluorinated hydrocarbons. Occup Environ Med. 2000;57(9):577-81.

66. Rosenman KD, Reilly MJ, Kalinowski D. Work-related asthma and respiratory symptoms among workers exposed to metalworking fluids. Am J Ind Med. 1997;32(4):325-31. 
67. Massin N, Bohadana AB, Wild P, Héry M, Toamain JP, Hubert G. Respiratory symptoms and bronchial responsiveness in lifeguards exposed to nitrogen trichloride in indoor swimming pools. Occup Environ Med. 1998;55(4):258-63.

68. Magnavita N. Cacosmia in healthy workers. Br J Med Psychol. 2001;74(Pt 1):121-7.

69. Lyons RA, Temple JM, Evans D, Fone DL, Palmer SR. Acute health effects of the Sea Empress oil spill. J Epidemiol Community Health. 1999;53(5):306-10.

70. Meo SA, Al-Drees AM, Rasheed S, Meo IM, Al-Saadi MM, Ghani HA, Alkandari JR. Health complaints among subjects involved in oil cleanup operations during oil spillage from a Greek tanker "Tasman Spirit". Int J Occup Med Environ Health. 2009;22(2):143-8.

71. Lee CH, Kang YA, Chang KJ, Kim CH, Hur JI, Kim JY, Lee JK. Acute health effects of the Hebei oil spill on the residents of Taean, Korea. J Prev Med Public Health. 2010;43(2):166-73. Korean.

72. Liu YH, Du CL, Lin CT, Chan CC, Chen CJ, Wang JD. Increased morbidity from nasopharyngeal carcinoma and chronic pharyngitis or sinusitis among workers at a newspaper printing company. Occup Environ Med. 2002;59(1):18-22.

73. Black DW, Okiishi C, Schlosser S. The Iowa follow-up of chemically sensitive persons. Ann N Y Acad Sci. 2001;933: $48-56$.

74. de la Hoz RE, Shohet MR, Cohen JM. Occupational rhinosinusitis and upper airway disease: the world trade center experience. Curr Allergy Asthma Rep. 2010;10(2):77-83.

75. Webber MP, Gustave J, Lee R, Niles JK, Kelly K, Cohen HW, Prezant DJ. Trends in respiratory symptoms of fire fighters exposed to the world trade center disaster: 2001-2005. Environ Health Perspect. 2009;117(6):975-80.

76. Longo BM, Rossignol A, Green JB. Cardiorespiratory health effects associated with sulphurous volcanic air pollution. Public Health. 2008;122(8):809-20.

77. Longo BM. The Kilauea Volcano adult health study. Nurs Res. 2009;58(1):23-31.

78. Longo BM, Yang W, Green JB, Crosby FL, Crosby VL. Acute health effects associated with exposure to volcanic air pollution (vog) from increased activity at Kilauea Volcano in 2008. J Toxicol Environ Health A. 2010;73(20):1370-81.

79. Ishigami A, Kikuchi Y, Iwasawa S, Nishiwaki Y, Takebayashi T, Tanaka S, Omae K. Volcanic sulfur dioxide and acute respiratory symptoms on Miyakejima island. Occup Environ Med. 2008;65(10):701-7.

80. Schiffman SS, Walker JM, Dalton P, Lorig TS, Raymer JH, Shusterman D, Williams CM. Potential health effects of odor from animal operations, wastewater treatment, and recycling of byproducts. J Agromed. 2004;9(2):397-403.

81. Athanasiou M, Makrynos G, Dounias G. Respiratory health of municipal solid waste workers. Occup Med (Lond). 2010;60(8): 618-23.

82. Wing S, Wolf S. Intensive livestock operations, health, and quality of life among eastern North Carolina residents. Environ Health Perspect. 2000;108(3):233-8.

83. Schinasi L, Horton RA, Guidry VT, Wing S, Marshall SW, Morland KB. Air pollution, lung function, and physical symptoms in communities near concentrated Swine feeding operations. Epidemiology. 2011;22(2):208-15.

84. Bener A, Lestringant GG, Beshwari MM, Pasha MA. Respiratory symptoms, skin disorders and serum IgE levels in farm workers. Allerg Immunol (Paris). 1999;31(2):52-6.

85. Apte MG, Fisk WJ, Daisey JM. Associations between indoor $\mathrm{CO} 2$ concentrations and sick building syndrome symptoms in US office buildings: an analysis of the 1994-1996 BASE study data. Indoor Air. 2000;10(4):246-57.
86. Mendell MJ, Lei-Gomez Q, Mirer AG, Seppänen O, Brunner G. Risk factors in heating, ventilating, and air-conditioning systems for occupant symptoms in US office buildings: the US EPA BASE study. Indoor Air. 2008;18(4):301-16.

87. Mendell MJ, Fisk WJ, Deddens JA, Seavey WG, Smith AH, Smith DF, Hodgson AT, Daisey JM, Goldman LR. Elevated symptom prevalence associated with ventilation type in office buildings. Epidemiology. 1996;7(6):583-9.

88. Costa MF, Brickus LS. Effect of ventilation systems on prevalence of symptoms associated with "sick buildings" in Brazilian commercial establishments. Arch Environ Health. 2000;55(4): 279-83.

89. Apte MG, Buchanan IS, Mendell MJ. Outdoor ozone and building-related symptoms in the BASE study. Indoor Air. 2008;18(2):156-70.

90. Buchanan IS, Mendell MJ, Mirer AG, Apte MG. Air filter materials, outdoor ozone and building-related symptoms in the BASE study. Indoor Air. 2008;18(2):144-55.

91. Kinshella MR, Van Dyke MV, Douglas KE, Martyny JW. Perceptions of indoor air quality associated with ventilation system types in elementary schools. Appl Occup Environ Hyg. 2001;16(10):952-60.

92. Koskinen OM, Husman TM, Meklin TM, Nevalainen AI. The relationship between moisture or mould observations in houses and the state of health of their occupants. Eur Respir J. 1999;14(6):1363-7.

93. Purokivi MK, Hirvonen MR, Randell JT, Roponen MH, Meklin TM, Nevalainen AL, Husman TM, Tukiainen HO. Changes in pro-inflammatory cytokines in association with exposure to moisture-damaged building microbes. Eur Respir J. 2001;18(6): 951-8.

94. Lötsch J, Ahne G, Kunder J, Kobal G, Hummel T. Factors affecting pain intensity in a pain model based upon tonic intranasal stimulation in humans. Inflamm Res. 1998;47(11): 446-50.

95. Jammes Y, Delvolgo-Gori MJ, Badier M, Guillot C, Gazazian G, Parlenti L. One-year occupational exposure to a cold environment alters lung function. Arch Environ Health. 2002;57(4): $360-5$.

96. Reinikainen LM, Jaakkola JJ. Effects of temperature and humidification in the office environment. Arch Environ Health. 2001;56(4):365-8.

97. Mohammadian P, Schaefer D, Hummel T, Kobal G. Experimentally induced nasal irritation. Rhinology. 1999;37(4):175-8.

98. Cruz AA, Togias A. Upper airways reactions to cold air. Curr Allergy Asthma Rep. 2008;8(2):111-7.

99. Mäkinen TM, Juvonen R, Jokelainen J, Harju TH, Peitso A, Bloigu A, Silvennoinen-Kassinen S, Leinonen M, Hassi J. Cold temperature and low humidity are associated with increased occurrence of respiratory tract infections. Respir Med. 2009; 103(3):456-62.

100. Hahn R. Clinical evaluation of flurbiprofen alone and plus ampicillin in chronic pharyngitis in acute phase. Int $\mathrm{J}$ Clin Pharmacol Res. 1986;6(1):81-6.

101. Li MA, Wang F. Review of acupuncture treatment for chronic pharyngitis. Zhongguo Zhen Jiu. 2010;30(4):349-51. Chinese.

102. Shi Y, Gu R, Liu C, Ni J, Wu T. Chinese medicinal herbs for sore throat. Cochrane Database Syst Rev. 2007;(3):CD004877.

103. Shevrygin BV, Fedorova TV, Pekli FF. Natural ether oils in the treatment of chronic pharyngitis in children in pediatric practice. Vestn Otorinolaringol. 1999;2:52-3. In Russian.

104. Bozhko AV. The effectiveness of the tablet form of an antiseptic drug with acute respiratory viral infections. Attending physician. 2008 Jan;1. Available at: www.lvrach.ru [In Russian].

105. Cadeddu L, Piragine F, Puxeddu P, Scornavacche V, SellariFranceschini S. Comparison of nimesulide and flurbiprofen in 
the treatment of non-infectious acute inflammation of the upper respiratory tract. J Int Med Res. 1988;16(6):466-73.

106. Renner B, Clarke G, Grattan T, Beisel A, Mueller C, Werner U, Kobal G, Brune K. Caffeine accelerates absorption and enhances the analgesic effect of acetaminophen. J ClinPharmacol. 2007; 47(6):715-26.

107. Tazeh-Kand NF, Eslami B, Mohammadian K. Inhaled fluticasone propionate reduces postoperative sore throat, cough, and hoarseness. Anesth Analg. 2010;111(4):895-8.

108. Park SY, Kim SH, Lee AR, Cho SH, Chae WS, Jin HC, Lee JS, Kim YI. Prophylactic effect of dexamethasone in reducing postoperative sore throat. Korean J Anesthesiol. 2010;58(1):15-9.

109. Rudra A, Ray S, Chatterjee S, Ahmed A, Ghosh S. Gargling with ketamine attenuates the postoperative sore throat. Indian J Anaesth. 2009;53(1):40-3.

110. Agarwal A, Nath SS, Goswami D, Gupta D, Dhiraaj S, Singh PK. An evaluation of the efficacy of aspirin and benzydamine hydrochloride gargle for attenuating postoperative sore throat: a prospective, randomized, single-blind study. Anesth Analg. 2006;103(4):1001-3.

111. Ebneshahidi A, Mohseni M. Strepsils ${ }^{\circledR}$ tablets reduce sore throat and hoarseness after tracheal intubation. Anesth Analg. 2010; 111(4):892-4.

112. Agarwal A, Gupta D, Yadav G, Goyal P, Singh PK, Singh U. An evaluation of the efficacy of licorice gargle for attenuating postoperative sore throat: a prospective, randomized, singleblind study. Anesth Analg. 2009;109(1):77-81.

113. Ogata J, Minami K, Horishita T, Shiraishi M, Okamoto T, Terada $\mathrm{T}$, Sata $\mathrm{T}$. Gargling with sodium azulenesulfonate reduces the postoperative sore throat after intubation of the trachea. Anesth Analg. 2005;101(1):290-3.

114. Woodin MA, Hauser R, Liu Y, Smith TJ, Siegel PD, Lewis DM, Tollerud DJ, Christiani DC. Molecular markers of acute upper airway inflammation in workers exposed to fuel-oil ash. Am $\mathbf{J}$ Respir Crit Care Med. 1998;158(1):182-7.

115. Fireman EM, Lerman Y, Ganor E, Greif J, Fireman-Shoresh S, Lioy PJ, Banauch GI, Weiden M, Kelly KJ, Prezant DJ. Induced sputum assessment in New York City fire fighters exposed to World trade center dust. Environ Health Perspect. 2004;112(15): 1564-9.

116. Park SY, Kim SH, Lee SJ, Chae WS, Jin HC, Lee JS, Kim SI, Hwang KH. Application of triamcinolone acetonide paste to the endotracheal tube reduces postoperative sore throat: a randomized controlled trial. Can J Anaesth. 2011;58(5):436-42.

117. Puyo CA, Tricomi SM, Dahms TE. Early biochemical markers of inflammation in a swine model of endotracheal intubation. Anesthesiology. 2008;109(1):88-94.

118. Jaensson M, Olowsson LL, Nilsson U. Endotracheal tube size and sore throat following surgery: a randomized-controlled study. Acta Anaesthesiol Scand. 2010;54(2):147-53.

119. Loeser EA, Kaminsky A, Diaz A, Stanley TH, Pace NL. The influence of endotracheal tube cuff design and cuff lubrication on postoperative sore throat. Anesthesiology. 1983;58(4):376-9.

120. SacreHazouri JA. Allergic rhinitis. Coexistent diseases and complications. A review and analysis. Rev Alerg Mex. 2006; 53(1):9-29. Spanish.

121. Proud D, Reynolds CJ, Lacapra S, Kagey-Sobotka A, Lichtenstein LM, Naclerio RM. Nasal provocation with bradykinin induces symptoms of rhinitis and a sore throat. Am Rev Respir Dis. 1988;137(3):613-6.

122. Norman PS, Naclerio RM, Creticos PS, Togias A, Lichtenstein LM. Mediator release after allergic and physical nasal challenges. Int Arch Allergy Appl Immunol. 1985;77(1-2):57-63.

123. Van Houtte E, Van Lierde K, Claeys S. Pathophysiology and treatment of muscle tension dysphonia: a review of the current knowledge. J Voice. 2011;25(2):202-7.
124. Grilo A, Sáez-Rosas MP, Santos-Morano J, Sánchez E, MorenoRey C, Real LM, Ramírez-Lorca R, Sáez ME. Identification of genetic factors associated with susceptibility to angiotensinconverting enzyme inhibitors-induced cough. Pharmacogenet Genomics. 2011;21(1):10-7.

125. Buhl R. Local oropharyngeal side effects of inhaled corticosteroids in patients with asthma. Allergy. 2006;61(5):518-26.

126. Kwong KK. Prevention and treatment of oropharyngeal mucositis following cancer therapy: are there new approaches? Cancer Nurs. 2004;27(3):183-205.

127. Murthy P, Laing MR. Cigarette smoking and sore throats in adults. Postgrad Med J. 1995;71(838):510.

128. Dye JA, Adler KB. Effects of cigarette smoke on epithelial cells of the respiratory tract. Thorax. 1994;49(8):825-34.

129. Renner B, Meindorfner F, Kaegler M, Thurauf N, Barocka A, Kobal G. Discrimination of R and S-nicotine by the trigeminal nerve. Chem Senses. 1998;23:602. Abstract.

130. Thuerauf N, Markovic K, Braun G, Bleich S, Reulbach U, Kornhuber J, Lunkenheimer J. The influence of mecamylamine on trigeminal and olfactory chemoreception of nicotine. Neuropsychopharmacology. 2006;31(2):450-61.

131. Shi Y, Weingarten TN, Mantilla CB, Hooten WM, Warner DO. Smoking and pain: pathophysiology and clinical implications. Anesthesiology. 2010;113(4):977-92.

132. Dilworth JP, White RJ, Brown EM. Oropharyngeal flora and chest infection after upper abdominal surgery. Thorax. 1991; 46(3):165-7.

133. Ussher M, West R, Steptoe A, McEwen A. Increase in common cold symptoms and mouth ulcers following smoking cessation. Tob Control. 2003;12(1):86-8.

134. Griesel AG, Germishuys PJ. Salivary immunoglobulin A levels of persons who have stopped smoking. Oral Surg Oral Med Oral Pathol Oral Radiol Endod. 1999;87(2):170-3.

135. Graham DE, Koren HS. Biomarkers of inflammation in ozoneexposed humans. Comparison of the nasal and bronchoalveolar lavage. Am Rev Respir Dis. 1990;142(1):152-6.

136. Frischer TM, Kuehr J, Pullwitt A, Meinert R, Forster J, Studnicka M, Koren H. Ambient ozone causes upper airways inflammation in children. Am Rev Respir Dis. 1993;148(4 Pt 1):961-4.

137. Ratto J, Wong H, Liu J, Fahy J, Boushey H, Solomon C, Balmes J. Effects of multiday exposure to ozone on airway inflammation as determined using sputum induction. Environ Health Perspect. 2006;114(2):209-12.

138. Pryor WA, Squadrito GL, Friedman M. The cascade mechanism to explain ozone toxicity: the role of lipid ozonation products. Free Radic Biol Med. 1995;19(6):935-41.

139. Nikasinovic L, Momas I, Seta N. Nasal epithelial and inflammatory response to ozone exposure: a review of laboratorybased studies published since 1985. J Toxicol Environ Health B Crit Rev. 2003;6(5):521-68.

140. Schiffman SS, Williams CM. Science of odor as a potential health issue. J Environ Qual. 2005;34(1):129-38.

141. Li N, Nel AE. The cellular impacts of diesel exhaust particles: beyond inflammation and death. Eur Respir J. 2006;27(4):667-8.

142. Huang YC, Li Z, Harder SD, Soukup JM. Apoptotic and inflammatory effects induced by different particles in human alveolar macrophages. Inhal Toxicol. 2004;16(14):863-78.

143. Auger F, Gendron MC, Chamot C, Marano F, Dazy AC. Responses of well-differentiated nasal epithelial cells exposed to particles: role of the epithelium in airway inflammation. Toxicol Appl Pharmacol. 2006;215(3):285-94.

144. Maciejewska A, Bielichowska-Cybula G. Biological effect of cement dust. Med Pr. 1991;42(4):281-9. Polish.

145. Lacroix JS, Landis BN. Neurogenic inflammation of the upper airway mucosa. Rhinology. 2008;46(3):163-5. 
146. Bessac BF, Jordt SE. Sensory detection and responses to toxic gases: mechanisms, health effects, and countermeasures. Proc Am Thorac Soc. 2010;7(4):269-77.

147. Verones B, Oortgiesen M. Neurogenic inflammation and particulate matter (PM) air pollutants. Neurotoxicology. 2001;22(6): 795-810.

148. Nilius B, Owsianik G, Voets T, Peters JA. Transient receptor potential cation channels in disease. Physiol Rev. 2007;87(1): 165-217.

149. Bessac BF, Jordt SE. Breathtaking TRP channels: TRPA1 and TRPV1 in airway chemosensation and reflex control. Physiology (Bethesda). 2008;23:360-70.

150. Bandell M, Story GM, Hwang SW, Viswanath V, Eid SR, Petrus MJ, Earley TJ, Patapoutian A. Noxious cold ion channel TRPA1 is activated by pungent compounds and bradykinin. Neuron. 2004;41(6):849-57.

151. Schumacher MA. Transient receptor potential channels in pain and inflammation: therapeutic opportunities. Pain Pract. 2010;10(3): 185-200.

152. Damann N, Voets T, Nilius B. TRPs in our senses. Curr Biol. 2008;18(18):R880-9.

153. Philip G, Togias AG. Nonallergic rhinitis. Pathophysiology and models for study. Eur Arch Otorhinolaryngol. 1995;252(1): S27-32.

154. Hegland KW, Pitts T, Bolser DC, Davenport PW. Urge to cough with voluntary suppression following mechanical pharyngeal stimulation. Bratisl Lek Listy. 2011;112(3):109-14.
155. Wright CE, Jackson J, Thompson RL, Morice AH. Validation of the ERS standard citric acid cough challenge in healthy adult volunteers. Cough. 2010;6:8.

156. Morice AH, Fontana GA, Belvisi MG, Birring SS, Chung KF, Dicpinigaitis PV, Kastelik JA, McGarvey LP, Smith JA, Tatar M, European Respiratory Society (ERS). ERS guidelines on the assessment of cough. Eur Respir J. 2007;29(6):1256-76.

157. Schachtel BP, Fillingim JM, Thoden WR, Lane AC, Baybutt RI. Sore throat pain in the evaluation of mild analgesics. Clin Pharmacol Ther. 1988;44(6):704-11.

158. Schachtel BP, Pan S, Kohles JD, Sanner KM, Schachtel EP, Bey M. Utility and sensitivity of the sore throat pain model: results of a randomized controlled trial on the COX-2 selective inhibitor valdecoxib. J Clin Pharmacol. 2007;47(7):860-70.

159. Yamabe M, Hosokawa T, Taoka T, Misawa M. A new pharyngitis model using capsaicin in rats. Gen Pharmacol. 1998;30(1): 109-14.

160. Lima-Rodrigues M, Valle-Fernandes A, Lamas N, Cruz A, Baltazar F, Milanezi F, Nunes R, Reis RM, Pedrosa J, Castro AG, Almeida A. A new model of laryngitis: neuropeptide, cyclooxygenase, and cytokine profile. Laryngoscope. 2008;118(1):78-86.

161. Hauber HP, Rüller S, Müller E, Hansen E, Zabel P. Pharyngeal lavage lymphocytosis in patients with obstructive sleep apnea: a preliminary observation. PLoS ONE. 2011;6(1):e16277. 